\title{
ASPECTOS REGULATÓRIOS EM UM NOVO MODELO PARA O SETOR DE SANEAMENTO BÁSICO NO BRASIL
}

\author{
Floriano de AZEVEdo MARques Neto* \\ "Se tens que lidar com água, primeiro fale com a experiência." \\ Leonardo da Vinci
}

1. Introdução - 2. Os principais problemas regulatórios do setor -3 . Possiveis modelos para o setor - 4. Elaboração de regras de regulação jurídica e econômica dos serviços - 5. Proposta das ações necessárias para criação de agência reguladora - 6. Proposta para participação de representantes dos municípios e usuários - 7. A questão ambiental e uso dos recursos hídricos -8 . Proposta para usos múltiplos e/ou exclusivos da água para consumo humano - 9. Avaliação dos índices de cobertura - 10. Instrumentos necessários para implementação das propostas aprovadas - 11. Implementação do marco regulatório e elaboração de legislação pertinente - 12. Interface entre o poder concedente e a concessionária - 13. Fiscalização da execução dos serviços - 14. Estrutura de penalidades contratuais e administrativas - 15. Casos de extinção da concessão e reversibilidade dos bens - 16. Prazos de concessão e condições para prorrogação dos contratos - 17. Os direitos e deveres dos usuários para obtenção e utilização dos serviços - 18. Proposta de estabelecimento de critérios, indicadores, fórmulas e parâmetros sobre a qualidade dos serviços - 19. Critérios para o cálculo da forma de pagamento de indenizações às concessionárias - 20. A solução das divergências contratuais entre o poder concedente e a concessionária - 21. O financiamento dos investimentos predominantemente de caráter social -22 . Conclusão.

* Advogado, Professor da Faculdade de Direito da PUC-SP. Doutor em Direito Público pela Universidade de São Paulo.

R. Dir. Adm.,

Rio de Janeiro, 224: 79-94,

abr./jun. 2001 


\section{Introdução}

O estabelecimento de marcos regulatórios claros e precisos é essencial para o êxito de qualquer processo de desestatização. No caso de empresas de saneamento, tal necessidade se mostra ainda mais nítida diante das peculiaridades que envolvem a regulação no setor. É fora de dúvida que o abastecimento de água e o esgotamento sanitário constituem serviços essenciais, tradicionais serviços públicos. Para além disso, são tais serviços imprescindíveis para o desenvolvimento econômico e social e para a própria saúde pública, como aliás prevê a Lei $\mathbf{n}^{\circ} 8.080 / 90$ (Lei do SUS, artigo $6^{\circ}$, II). Há também que se destacar o fato de que, afora o impacto social destes serviços, somente com a definição de um sólido panorama regulatório é que é possível oferecer aos investidores alguma certeza num processo permeado por problemas complexos como a titularidade do serviço, manejo de recursos hídricos ou panorama ambiental. Neste sentido, o desenvolvimento dos marcos regulatórios concomitantemente ao desenvolvimento da modelagem de venda se põe central na discussão do tema.

\section{Os principais problemas regulatórios do setor}

Aos problemas regulatórios típicos de todos os setores ligados à produção de utilidades públicas agregam-se, no setor de saneamento, outros ainda mais complexos. O primeiro deles diz respeito à definição acerca da titularidade dos serviços de saneamento, havendo acesa polêmica entre a titularidade municipal e estadual. Para enfrentamento desta questão, com efetiva garantia ao processo de desestatização, é necessário o desenvolvimento de mecanismos de articulação entre o poder público municipal e estadual de modo a deixar fora de dúvida a titularidade à prestação dos serviços. Alternativas várias existem. Pode-se citar, por exemplo, a outorga de concessões por consórcios de Municípios (o que poderia ser precedido por um plano de outorgas com recomendação das regiões) ou mesmo o estabelecimento de contratos de concessão com os principais municípios com cessão de ações da concessionária a título de ônus. Neste último caso, pode-se vislumbrar a compartimentação da empresa por região, efetuando em maior ou menor grau uma municipalização do serviço.

O outro problema diz respeito ao regime de utilização de recursos hídricos. É sabido que a atividade de saneamento é indissociável da utilização da água. Assim, para além de representar um serviço público essencial, constitui uma atividade diretamente atrelada a um bem público escasso, de titularidade federal ou estadual. Daí porque podemos dizer que o setor de saneamento reune problemas regulatórios próprios de serviços públicos (como telecomunicações e energia) com problemas encontrados no segmento do petróleo.

A legislação referente aos recursos hídricos tem avançado significativamente. Em 10.09.91 fora editado Decreto criando o Comitê Nacional de Saneamento. Já em 08.01.97 adveio a Lei n 9.433, "Lei de Recursos Hídricos", que trouxe modificações relevantes à fixação do critério de outorga de direito de uso da água e cobrança pelo 
mesmo, além da fixação das bacias hidrográficas e de seus respectivos comitês, criados para gerenciar os recursos hídricos delas provenientes. $\mathrm{Na}$ esteira desta legislação encontra-se no Congresso o Projeto de Lei sobre as "Agências de Água" às quais incumbe controlar o uso dos recursos hídricos, até mesmo mediante a cobrança pelo seu uso e projeto estabelecendo as diretrizes para o exercício do poder concedente na esfera federal para a prestação, delegação e regulação dos serviços de saneamento básico (PLS $n^{\circ}$ 266/96). Embora controladas por Comitês de Bacias Hidrográficas, as Agências de Água exercem um papel de impacto direto na atividade de saneamento. Além disso, encontram-se em fase final de elaboração (já tendo sido postos em audiências públicas) Decretos que tratam de regulamentar os Comitês de Bacias Hidrográficas, a outorga onerosa de direito de uso de recursos hídricos e que aprovam o regulamento do sistema nacional de informações sobre recursos hídricos.

Fato é que o estabelecimento de marcos regulatórios para o setor deve envolver um profundo levantamento de toda a legislação referente aos recursos hídricos, de modo a tornar sua regulação aderente à regulação que está sendo editada sobre o principal elemento para esta indústria específica. Tudo isso deve levar em conta os impactos ambientais e econômicos, posto que se caminha para incrementar a cobrança pelo uso dos recursos hídricos, pois se projeta, para o próximo século, uma situação de escassez de recursos hídricos, havendo quem anteveja a transformação da água em uma mercadoria negociável em estado bruto.

\section{Possiveis modelos para o setor}

A reestruturação do setor de saneamento no Brasil envolve o desenvolvimento de novos modelos, os quais devem implicar, certamente, na definição de um novo ordenamento institucional e jurídico, observando princípios básicos e necessários à perfeita regulação do setor.

Tais modelos devem contemplar, obrigatoriamente, a articulação dos mecanismos de regulação exercidos pela União, pelos Estados e Municípios, de forma a estabelecer: i) a titularidade das respectivas competências; ii) a nova estrutura dos poderes concedentes; iii) a criação de um órgão regulador; iv) a exigência de licitação para novas concessões; v) a definição da estrutura dos prestadores de serviço; por fim, vi) definição e compatibilização das políticas públicas dos diferentes entes, especialmente no que tange à articulação e à definição de novas diretrizes relacionadas a áreas de competência legislativa exclusiva, complementares ou subsidiárias, tais como nas áreas de saúde, proteção ambiental, tributos e economia.

Por outro lado, a fixação de um novo modelo articulado de regulação faz-se necessária a fim de amenizar os conflitos de competência verificados na análise da situação atual. Notadamente porque critérios técnico-operacionais e econômico-financeiros podem conduzir à conclusão acerca da necessidade de redefinição geográfica e/ou setorial da atual distribuição da prestação dos serviços de saneamento.

Dessa forma, é necessária a elaboração de instrumentos institucionais para essa redefinição, delimitando novas competências, mais adequadas ao modelo proposto, na forma do disposto no parágrafo único do artigo 23 da Constituição Federal, de 
modo a se propiciar um ambiente de eficiência e modernidade no setor, por intermédio da melhoria dos padrões de qualidade e produtividade.

Conforme determina o referido preceito constitucional, o rearranjo das competências deve ser instituído por lei complementar que, obrigatoriamente, busque a manutenção e preservação das políticas de desenvolvimento municipais, estaduais, regionais e federais.

De outro lado, as análises técnico-operacionais e econômico-financeiras podem delinear o novo modelo definindo a segmentação da prestação dos diferentes serviços (abastecimento de água, esgotamento sanitário, coleta e tratamento de resíduos sólidos, drenagem urbana, vigilância sanitária, saúde pública e higiene ambiental) que compõem o saneamento básico.

O novo modelo institucional a ser proposto deve compreender os instrumentos jurídicos necessários a essa segmentação e que ofereçam garantias a cada um dos prestadores de serviço para atender às condições necessárias à manutenção da qualidade de atendimento à população, bem como possibilitem a exigência pelo poder concedente do cumprimento das políticas e metas individuais e comuns a todos os concessionários. A remodelagem institucional deve ter em conta, principalmente, as políticas de universalização estabelecidas pelo governo federal, que programam a universalização do serviço de saneamento básico até o ano de 2010 .

Muito embora atuando em regiões geográficas distintas, os prestadores do serviço de saneamento, certamente, dependem uns dos outros, tanto em face dos limites naturais de disponibilidade dos recursos hídricos como para obter melhor aproveitamento das estruturas existentes e a serem criadas e maximização dos investimentos efetuados em cada região. A questão do grau de descentralização dos serviços de saneamento entre a esfera estadual e municipal, e eventualmente de segmentação da empresa estadual de saneamento por região geográfica também deve ser enfrentada.

Ainda seguindo as determinações decorrentes das análises técnico-operacionais e econômico-financeiras, as sugestões de modelos devem contemplar formas distintas de participação da iniciativa privada no setor. A estipulação de tais formas decorre da necessidade de se compatibilizar o interesse econômico da empresa com o caráter eminentemente social do serviço, tendo em vista se tratar de condição essencial de saúde pública e saneamento ambiental.

A prestação dos serviços à população carente, dada a sua baixa rentabilidade, certamente inviabiliza a suficiente remuneração do investimento privado, o que implica na necessidade de proposição de modelo específico de transferência da atividade à iniciativa privada, provavelmente por meio da implantação de contratos de gestão sem alienação de patrimônio em certas regiões, sendo certo que a obrigação de investimento permanece a cargo do Estado. Trata-se do contrato de B.O.T. (buy, operate \& transfer), ou de suas variações, pelo qual a iniciativa privada assume a gestão e realiza investimentos durante certo período, restituindo os ativos ao patrimônio público com o término do contrato.

Assim sendo, o novo modelo para o setor deve oferecer os instrumentos jurídicos necessários tanto à implantação do regime da concessão propriamente dita, quanto dos contratos de gestão. 
A análise da experiência francesa é de grande valia neste sentido. O modelo francês caracteriza-se por grande descentralização e forte participação da iniciativa privada. A França desenvolveu um plexo de contratos de associação entre o setor privado e o Poder Público, sem transferência dos ativos públicos. Os contratos vão desde o gerenciamento (gérance), pelo qual o particular é remunerado com taxa fixa, até a concessão (concession), em que o particular restitui as instalações à Administração local ao final do contrato.

A proposição dos novos modelos, adotados o regime da concessão ou da gestão, deve compreender a elaboração dos marcos regulatórios e contratos, com a fixação das atribuições do poder concedente e a estipulação dos órgãos que o representam na relação com os novos prestadores de serviço.

Nas hipóteses em que for adotado o regime da concessão, o modelo contempla as funções a serem exercidas pelas entidades representantes do poder concedente, podendo-se destacar a fiscalização dos serviços, a fixação da tarifa e a verificação da aplicação dos investimentos mínimos e níveis de atendimento, de forma a garantir a prestação dos serviços com a observância dos princípios do artigo $6^{\circ}$, da Lei $n^{\circ}$ $8.987 / 95$.

De outro lado, nos casos em que for adotado o regime da gestão da operação, o modelo deve prever, além das funções reguladoras do poder concedente, a obrigação deste de efetuar os investimentos necessários à adequação, expansão e melhoria dos serviços.

Merece atenção, ainda, a compatibilização dos instrumentos jurídicos a serem criados com as normas regulatórias da repressão ao abuso do poder econômico (Lei $\mathrm{n}^{\circ} 4.137$, de 10 de setembro de 1962 e Lei $\mathrm{n}^{\circ} 8.137$, de 27.12 .90 ) e defesa da concorrência (Lei $n^{\circ} 8.158$, de 8 de janeiro de 1991 e Lei $n^{\circ} 8.884$, de 13.06.94), objetivando, de um lado, evitar o indesejável aumento imotivado do custo dos serviços prestados e, de outro, propiciar a livre concorrência e a liberdade de iniciativa, que, sem dúvida, beneficiam, diferentemente da atual situação, os consumidores finais.

A fiscalização e a estipulação das diretrizes a serem seguidas pelos novos prestadores de serviço, devem ficar a cargo das entidades governamentais estipuladas nos respectivos marcos regulatórios, com participação direta da população atendida pelos concessionários, de forma a possibilitar uma melhor adequação dos serviços às necessidades locais, respeitando-se, conseqüentemente, o direito dos usuários, nos exatos termos do que estabelecem os artigos 175 , IV e $37, \S 3^{\circ}$ da Constituição Federal.

Igualmente importante, na definição dos modelos, é a compatibilização da nova estrutura legal às recentes alterações legislativas, que atingem diretamente o setor de saneamento, especialmente a "Lei de Recursos Hídricos", onde são definidos critérios de outorga de direito de uso da água e prevista a criação de comitês para o gerenciamento das bacias, entre outras inovações relevantes para a adequação e modernidade do saneamento básico.

Os novos modelos a serem propostos devem compreender os instrumentos jurídicos necessários a garantir aos futuros operadores o acesso aos recursos hídricos, 
imprescindíveis à prestação dos serviços atinentes ao saneamento básico, com a outorga aos mesmos dos respectivos direitos de uso.

Da mesma forma, a nova modelagem deve adequar-se à regulamentação acerca das bacias hidrográficas instituída pela supra aludida lei, sendo certo que as duas alterações dela decorrentes, ora enfocadas, ocasionam também a propositura de uma redistribuição das competências entre os entes públicos Federal, Estaduais e Municipais, levando em conta a legitimidade para outorga do direito de uso dos recursos hídricos, exclusiva da União, Estados ou Distrito Federal, bem como a competência para regular as bacias hidrográficas.

Tendo em vista as inúmeras inovações a serem propostas com a nova modelagem (especialmente no que tange à distribuição da competência e redefinição da divisão geográfica ou setorial dos serviços de saneamento básico e os aspectos de integração com outras políticas públicas), ensejadoras de novas iniciativas legislativas e de instrumentos jurídicos de difícil implantação, deve-se considerar um período de transição entre o modelo atual e os propostos, de forma a impedir qualquer interrupção ou queda de qualidade na prestação dos serviços, absolutamente essenciais.

É de se destacar, outrossim, que a adoção de política de segmentação da prestação de serviços, em um ambiente altamente concentrado, pode ocasionar, num primeiro momento, algumas dificuldades, principalmente nas regiões e localidades menos estruturadas técnica e/ou financeiramente. Assim, deve ser enfatizada, nesta fase de transição do atual sistema para o novo modelo, a criação dos instrumentos jurídicos necessários à imediata atuação do poder concedente, no sentido de evitar o colapso, a interrupção ou a queda de qualidade dos serviços prestados.

Além disso, os mecanismos jurídicos devem também criar os instrumentos necessários a permitir a transferência dos serviços aos novos concessionários, com a observância de alguns requisitos mínimos técnico-operacionais, a serem definidos, que evitem qualquer prejuízo aos consumidores atendidos dentro da área de concessão.

\section{Elaboração de regras de regulação jurídica e econômica dos serviços}

É imprescindível o estabelecimento de um aparato de regulação jurídica e econômica dos serviços. Do ponto de vista jurídico, antevemos dois campos de relevância da regulação. $O$ primeiro relacionado a toda a montagem do arcabouço jurídico e institucional voltado à criação e ao funcionamento do órgão regulador do setor e à sua articulação com outros órgãos reguladores diretamente envolvidos no setor (em especial, na área do consumidor, no setor ambiental e com as Agências de Água). Relevante é, neste sentido, estudar os diversos modelos já praticados no exterior, deitando especial atenção àquele hoje vivenciado na Inglaterra.

O modelo inglês caracteriza-se pela criação de um órgão regulador autônomo ( $o$ Office of Water Services - OFWAT), dotado de grande poder regulatório, que estabelece tarifas, promove a proteção do consumidor, assegura os padrões de qualidade do serviço e cria incentivos à eficiência e à competitividade das companhias. 
A regulação da qualidade da água e do esgoto é feita pela Environment Agency e pelo Drinking Water Inspectorate.

Ainda no campo da regulação jurídica, é necessário desenvolver todo um arcabouço voltado a equacionar os impasses federativos acima apontados. A questão seria solucionada com a aprovação do Projeto de Lei Federal $n^{\circ}$ 266/96, atualmente no Senado Federal. Contudo, há controvérsia jurídica quanto à natureza de lei ordinária destas disposições, motivo pelo qual o projeto encontra-se atualmente sem trâmite definido. Em consequiência, a solução do impasse federativo pode envolver tanto a elaboração de projetos de lei (principalmente para apreciação na esfera Estadual e Municipal) como também o suporte para efetivação dos instrumentos jurídicos negociais que envolvem a União, o Estado e os Municípios, isolados, em consórcio ou no âmbito das Regiões Metropolitanas. A tendência é a confirmação da regra que reconhece a competência estadual, atribuindo aos Estados a titularidade dos serviços nas áreas de interesse comum. A solução definitiva para a questão é especialmente relevante caso se opte por um modelo de estruturação do serviço que envolva a adesão dos Municípios ao programa de desestatização.

Igual importância deve ter a regulação econômica. Ela deve se manifestar, entre outros, no tocante aos mecanismos regulatórios relativos aos investimentos na universalização dos serviços, na explicitação dos custos e eventuais subsídios internos aos diversos serviços, na eventual hipótese de se evoluir para uma perspectiva de competição nos serviços e, principalmente, na definição da política tarifária a ser desenvolvida.

Neste ponto em particular, se colocam algumas questões de grande relevância. A política tarifária no setor de saneamento deve enfrentar a questão do subsídio entre classes de consumidores e a discussão em torno de tarifas sociais, mormente no tocante às populações de baixíssima renda. $\mathrm{E}$ tal problema deve ser enfrentado na perspectiva de evitar a concentração tarifária nos grandes consumidores (que acabam por se esquivar do pagamento mediante recursos judiciais ou negociação de isenções) $\mathrm{e}$, de outro lado, superar o problema do aumento de inadimplência pelo consumidor de baixa renda, num momento de retração econômica. A experiência inglesa dos "price caps", patamares máximos de tarifas estabelecidos pelo órgão regulador para todas as operadoras, pode ser útil para análise do regulador brasileiro. Há risco, com efeito, que os grandes investimentos realizados pelo(s) concessionário(s) privado(s) venham a se traduzir em alta demasiada das tarifas praticadas.

A questão dos descontos para vendas por atacado ou para grandes consumidores industriais deve ser igualmente equacionada. Devem ser levados em conta fatores como a geração de empregos, receitas de impostos geradas, economia de consumo e soluções individuais de tratamento de esgoto (fossas). O consumidor individual não pode, no entanto, ser sobrecarregado pelo desconto oferecido aos grande usuários.

Por fim, a regulação econômica não pode descurar do fato de que, internacionalmente, os grandes atores econômicos atuantes no setor começam a se organizar em torno de "multi utilities", reunindo atividades da indústria da água, energia, saneamento e resíduos sólidos em grandes grupos, com vistas à obtenção de escala capaz de alavancar pesados investimentos em novas tecnologias. 
A instituição de um órgão regulador independente e autônomo (seguindo o modelo de Agências) é ponto central na constituição de um marco regulador adequado para o setor. É preciso definir quais os instrumentos regulatórios de que este órgão regulador deve estar dotado e dimensionar a estrutura (financeira e de pessoal) imprescindível ao seu eficaz funcionamento. O estabelecimento de fontes próprias de receitas (para o que taxas de fiscalização constituem importante instrumento) se faz necessário para garantir a sua autonomia, livrando-a de amarras orçamentárias e diminuindo o risco de captura por subtração de meios. Dotar a Agência de mecanismos mais ágeis de gestão também constitui passo relevante.

Ainda com relação à peculiaridade do saneamento frente ao problema federativo, é importante verificar que o órgão regulador pode não ter poderes para outorga de concessões. Teríamos, então, um órgão regulador puro, desincumbido do papel de representante do titular do serviço, que poderia ser desempenhado, até mesmo, pelas Prefeituras. Esta alternativa teria a vantagem de tornar a Agência um pouco mais protegida da captura política, um dos maiores riscos para a regulação no setor. Por outro lado, é necessário desenvolver alguns instrumentos jurídicos complexos como, por exemplo, a possibilidade de ser decretada a caducidade por ente público não titular do serviço outorgado.

A respeito da criação da Agência, devem ser pensados instrumentos de articulação com outros órgãos reguladores afetos ao setor, o que pode envolver, até mesmo, a agência nacional de águas e a agência nacional de energia elétrica.

\section{Proposta para participação de representantes dos municípios e usuários}

Imprescindível é o estabelecimento de mecanismos de participação na atividade regulatória da Agência. No tocante à participação dos usuários, vários são os mecanismos que devem ser analisados, tais como a instituição de comitês de usuários dos serviços; a integração de entidades de representação de classes de usuários; a instituição da figura do ombudsman tanto na concessionária como no órgão regulador; a obrigatoriedade de que a concessionária tenha um serviço de atendimento ao consumidor, permanente e eficazmente acessível aos usuários; regras claras de publicidade ampla para os procedimentos da Agência; a obrigatoriedade de Consultas e Audiências Públicas para a prática dos atos relevantes do órgão regulador. Todos estes mecanismos, já encontradiços na legislação brasileira (vide Código de Defesa do Consumidor, Lei $n^{\circ} 9.472 / 97$, Lei $n^{\circ} 8.987 / 95$, entre outras), devem ser analisados e adaptados às peculiaridades do serviço, de modo a concretizar o pressuposto de ampla participação do usuário na atividade regulatória.

Igualmente indeclinável é a participação na Agência do poder público municipal. Esta participação deve envolver i) o processo de escolha dos dirigentes; ii) a instituição de conselhos consultivos com a participação de representantes dos Municípios; iii) a criação de comitês técnicos para os quais devem ser indicados membrós pelos Municípios, entre outros mecanismos. O fato é que nos parece que, na regulação do 
setor de saneamento, deva estar presente um vetor de descentralização regulatória que, sem prescindir de alguma centralização no âmbito estadual, incorpore a dimensão municipal no exercício da regulação, sem o que é posto em risco o modelo.

Neste sentido, os Comitês de Bacias Hidrográficas podem constituir foro adequado para a integração dos Municípios na regulação estadual. Os comitês podem adquirir uma conotação de verdadeiro pacto social a ser estabelecido entre as entidades federativas envolvidas, os beneficiários dos serviços de saneamento e a sociedade em geral, incluindo os representantes dos interesses de natureza ambiental e do consumidor.

\section{A questão ambiental e uso dos recursos hídricos}

Outro aspecto relevante, que merece atenção especial, refere-se à adequação da nova política de saneamento - e, consequientemente, dos seus instrumentos legais - ao arcabouço jurídico existente, relacionado à proteção e preservação do meio ambiente, notadamente à Lei $n^{\circ} 6.938$, de 31 de agosto de 1981, que define a Política Nacional de Meio Ambiente, cujo principal objetivo é a preservação e a recuperação da qualidade ambiental, atendendo, dentre outros aspectos, à racionalização do uso do solo, do subsolo e da água.

Deste modo e uma vez que o setor de saneamento, principalmente no que se refere às áreas de captação, tratamento e disposição dos resíduos sólidos, atua e interfere diretamente no meio ambiente, é dado especial enfoque a tais aspectos de modo a se evitar a adoção de qualquer mecanismo que possa conflitar com as mencionadas normas de proteção ambiental. $\mathrm{O}$ tratamento de esgotos e resíduos sólidos, pouquíssimo efetuado no Brasil, deve ser incentivado e privilegiado.

A questão ambiental se coloca também na interface com os aspectos econômicos. Uma vez que qualquer investimento para ampliação da rede de captação de água ou tratamento de esgoto envolve impactos ambientais significativos, é impossível trabalhar com metas de qualidade e ampliação dos serviços sem dedicar grande atenção ao aspecto ambiental. Por fim, é necessário lembrar que as crescentes exigências das normas e padrões do direito ambiental no tocante à água apontam para a necessidade de investimentos cada vez maiores. Segue daí que a regulação deve ter em vista que, por exemplo, a substituição de padrões tecnológicos de tratamento da água (com o abandono dos tratamentos químicos em favor de tecnologias de tratamento físico e biológico) pode introduzir gargalos de investimento incompatíveis, por exemplo, com a universalização do serviço. $O$ equilíbrio jurídico e institucional destas dimensões ambientais é um dos desafios do trabalho.

No tocante ao uso dos recursos hídricos, deve ser desenvolvido mecanismo que evite o desperdício de água pelos concessionários, privados ou públicos. Ainda que o concessionário passe a pagar pela água que fornece aos consumidores, os desperdícios da rede podem inviabilizar economicamente a operação comercial do concessionário, acarretando aumento nas tarifas ou déficit a ser sanado pelo Poder Público. Os municípios e entidades de usuários devem associar-se ao Estado em campanhas de combate ao desperdício e de conscientização de saneamento básico à população. 
Com efeito, tal participação é indispensável ao sucesso de uma política de aproveitamento máximo dos recursos hídricos, que deve contar ainda com a participação das entidades ligadas à saúde e com o apoio do governo federal.

\section{Proposta para usos múltiplos elou exclusivos da água para consumo humano}

O marco regulatório deve apresentar, em conjuminância com a Política Nacional de Recursos Hídricos, soluções para a questão do uso da água. E neste ponto, considerando as realidades das Bacias envolvidas, deve buscar o equilíbrio entre as diversas dimensões do uso destes recursos. Neste sentido, em conjunto com os estudos técnicos a serem desenvolvidos pelas equipes, devem ser propostos mecanismos de reserva de potenciais hídricos para uso exclusivo para consumo humano $e$, de outro lado, mecanismos regulamentares e contratuais voltados a compatibilizar o uso múltiplo com os marcos da política de saneamento.

\section{Avaliação dos índices de cobertura}

Para que possam ser estabelecidos parâmetros de qualidade e expansão da rede é necessário desenvolver padrões confiáveis de avaliação de cobertura. Para tanto, é necessária uma pesquisa comparada com os critérios adotados internacionalmente, atualizando-se e complementando-se os índices hoje adotados, em especial os critérios de ligações domiciliares e de perfil econômico. Devem, ainda, ser considerados o porcentual de crescimento demográfico da população, o desenvolvimento de loteamentos urbanos, o plano diretor municipal. De outro lado, a avaliação destes índices deve ser aderente à perspectiva de metas de universalização e de qualidade que se quer implementar, considerando também a baixa penetração do serviço de saneamento básico no Estado.

Mais uma vez o modelo inglês pode servir de baliza para o regulador brasileiro. A Inglaterra adotou o mecanismo de yardstick competition, ou competição por padrões de comparação, que compara os desempenhos de todas as empresas atuando no setor, exigindo da concessionária o cumprimento dos índices médios verificados em outras empresas similares.

Ainda, no caso de descentralização parcial dos serviços de saneamento, por meio de cessão de ações das concessionárias do serviço aos Municípios, deve ser viabilizada estrutura de assistência técnica e capacitação de pessoal na operação de serviços de saneamento para pequenos municípios e comunidades de pequeno porte e rurais.

\section{Instrumentos necessários para implementação das propostas aprovadas}

Vários devem ser os instrumentos para implementação das propostas aprovadas no âmbito regulatório. Num primeiro plano, estão os instrumentos legais voltados 
especialmente a i) equacionar o problema das outorgas e da definição de competências municipais e estaduais; ii) autorizar a concessão dos serviços (Cf. artigo $2^{\circ}$ da Lei Federal $n^{\circ}$ 9.074/95); iii) estabelecer os critérios de uso dos recursos hídricos estaduais, em consonância com a legislação federal sobre o tema; iv) instituir e aparelhar a Agência regulatória do setor; v) estabelecer os mecanismos de proteção dos direitos dos usuários dos serviços.

No âmbito da macro regulação, é necessário desenvolver minutas de contratos de concessão dos serviços, adaptando-as às diversas situações que são estabelecidas no relacionamento com os Municípios. Além disso, devem ser elaborados os documentos regulatórios definidores da política para o setor, como por exemplo, planos diretores, de outorgas, de metas de qualidade e de universalização.

Por fim, é necessária a elaboração de documentos regulamentares, que devem, entre outras atribuições i) reger o funcionamento interno da Agência, sua gestão e procedimentos; ii) regulamentar a prestação dos serviços.

\section{Implementação do marco regulatório e elaboração de legislação pertinente}

A definição dos marcos regulatórios para o setor não prescinde da adoção de mecanismos de interlocução entre as três esferas da federação, em especial com os Municípios. Essa interlocução deve ser feita institucionalmente, mas pode passar pela negociação envolvendo: i) a outorga formal de concessões pelos Municípios em favor da Compesa; ii) o envolvimento dos Municípios na atividade regulatória e de definição das políticas de universalização, qualidade e, conforme a modelagem, tarifária. Essa alternativa, como visto, acarreta um maior percurso jurídico e institucional, mas daria maior segurança para os investidores.

Outra alternativa é a de se travar entendimentos em torno de um protocolo de adesão dos Municípios ao programa de concessão estadual, em especial nas regiões metropolitanas. Neste caso, atalha-se o caminho institucional sem, contudo, conferir segurança ao modelo.

De todo modo, da implementação dos marcos regulatórios devem participar todos os atores políticos envolvidos, podendo se sugerir que a articulação destes seja realizada pelo Governo Estadual, podendo passar, até mesmo, pela aprovação de Lei Complementar Estadual (artigo $25, \S 3^{\circ}$ da Constituição Federal).

\section{Interface entre o poder concedente e a concessionária}

A relação de concessão é, normalmente, tripartida. Dela fazem parte, com interesses nem sempre convergentes, o poder concedente, o concessionário e o usuário do serviço. No caso do saneamento, há uma gama maior de atores. Há o detentor do recurso escásso imprescindível ao serviço (água) que pode ser o Estado ou a União. E há a já aludida indefinição acerca de qual esfera federativa seja o poder concedente. Neste sentido é que se põe necessária a separação entre órgão regulador (estadual) e poder concedente (compartilhado). Neste quadrante, a inter- 
face entre poder concedente e as concessionárias deve ser mediada, necessariamente, pelo órgão regulador específico. E o veículo principal desta mediação deve ser o contrato de concessão.

A Lei $n^{\circ} 8.987 / 95$ conceitua poder concedente como podendo ser União, Estados, Distrito Federal ou Municípios, dependendo da competência do serviço público que se pretende conceder. $O$ mesmo artigo conceitua concessão de serviço público como sendo a delegação a pessoa jurídica ou consórcio de empresas, que demonstre capacitação, de um determinado serviço público, feita pelo poder concedente, mediante concorrência, por prazo determinado. Referido artigo conceitua, ainda, uma forma de concessão precedida de execução de obra pública, na qual a empresa ou consórcio concessionário se comprometem a construir, finalizar ou melhorar determinada obra de interesse público, obtendo seu pagamento da exploração do serviço ou da obra por prazo determinado.

Fixados os conceitos necessários à análise a que se propõe, mister destacar que, em atendimento ao ordenamento legal, os serviços objeto de concessões devem adequar-se a algumas condições mínimas, tais como regularidade, continuidade, eficiência, segurança, atualidade, generalidade, cortesia e modicidade tarifária. Devem ser resguardados, ainda, alguns direitos dos usuários dos respectivos serviços, também fixados pela legislação específica.

A exemplo da adequação dos serviços e dos direitos dos usuários, a política tarifária das concessionárias também deve seguir os parâmetros fixados nas disposições legais ora analisadas, sendo certo que a tarifa deve ser fixada pelo preço da proposta inicial, elaborada quando da licitação da concessão, com as revisões e correções previstas no respectivo edital, no contrato de concessão e na legislação específica.

Da mesma forma, deve-se dispensar especial atenção à análise dos procedimentos adotados na licitação das concessões e na elaboração dos respectivos contratos, de modo a verificar e providenciar o atendimento ao disposto pela legislação ora enfocada.

Por outro lado, no que se refere à outorga de novas concessões e à revalidação e prorrogação das concessões que dão suporte às atividades de saneamento, deve ser verificado o disposto pela Lei $n^{\circ} 9.074 / 95$, especificamente editada para disciplinar a outorga de concessões e a prorrogação das concessões existentes.

Referido texto legal fixa as condições de revalidação e outorga das concessões, bem como a forma de prorrogação das mesmas, que deve obedecer alguns preceitos básicos, tais como o prazo para apresentação do pedido de prorrogação e a necessidade de comprovação da capacidade técnica, jurídica e financeira do concessionário que pleiteia a prorrogação.

Assim sendo, o estudo das concessões deve passar imprescindivelmente pela análise e formulação de soluções para adequação das mesmas às disposições legais retro analisadas, de modo a garantir a regular prestação dos serviços.

\section{Fiscalização da execução dos serviços}

O marco regulatório - em especial $\cdot o$ contrato de concessão e o Plano de Qualidade - deve conter regras específicas sobre a fiscalização da prestação. Neste 
sentido, três grandes linhas devem ser observadas: i) a fiscalização contábil, voltada a verificar o cumprimento das metas de investimento e o regime dos ativos empregados no serviço; ii) a fiscalização operacional, voltada a aferir o cumprimento das metas de qualidade, ambientais e o modo de prestação; iii) a fiscalização do atendimento ao consumidor, voltada a aferir o cumprimento das metas e das condicionantes de adequação do serviço (Lei $\mathrm{n}^{\circ} 8.987 / 95$, artigo $6^{\circ}$ : regularidade, continuidade, eficiência, segurança, atualidade, generalidade, cortesia e modicidade nas tarifas). Quanto a esse último ponto, a regulação deve prever a transposição destes standards de adequabilidade à especificidade do saneamento.

Devem ser previstas duas ordens de atuação fiscalizadora: prospectiva e inquisitorial. A primeira, cuida de estabelecer obrigações para a prestadora encaminhar determinadas informações, com periodicidade preestabelecida. A segunda, trata de prever meios e procedimentos para auditorias e investigações pelo órgão regulador na atividade da prestadora. Prevemos também o estabelecimento de um procedimento investigatório e de fiscalização que devem constar de instrumentos regulatórios específicos.

A associação dos Municípios à atividade fiscalizatória deve ser privilegiada. Com efeito, a proximidade geográfica e a pulverização de núcleos de fiscalização podem tornar mais efetiva a incumbência da futura Agência Estadual de inspeção das condições do saneamento básico.

\section{Estrutura de penalidades contratuais e administrativas}

A atividade punitiva é um dos pilares centrais para o órgão regulador. Em princípio é necessário prever em lei um regime de sanções, sem o que resta frágil a atividade apenadora da Agência. É imprescindível o estabelecimento na regulamentação e no contrato de concessão de i) uma estrutura de condutas puníveis com as respectivas penas; ii) um regime de escusas de punibilidade, atenuantes e agravantes; iii) um procedimento sancionatório que assegure o direito de defesa e o devido processo legal.

A estrutura de penalidades deve prever, entre outras, sanções contra infrações i) que frustrem as metas de universalização dos serviços; ii) que afetem o meio ambiente; iii) que frustrem o consumidor; iv) que representem descumprimento de parâmetros de qualidade; v) que frustrem a atividade fiscalizadora da Agência; vi) que coloquem em risco bens reversíveis. A instituição de mecanismos de conversão das multas aplicadas aos concessionários, em benefício direto aos usuários prejudicados, deve ser cogitada, a exemplo do setor das telecomunicações e da energia elétrica.

\section{Casos de extinção da concessão e reversibilidade dos bens}

A legislação e o contrato para prestação dos serviços de saneamento devem prever as hipóteses de extinção da concessão. Elas devem compreender, além da 
hipótese de advento do termo contratual, a encampação (retomada do serviço pelo seu titular), caducidade (extinção da concessão por grave infração do concessionário), rescisão (desfazimento por iniciativa da concessionária ou avença entre as partes) e anulação (nas hipóteses de irregularidade insanável no contrato de concessão). Destas deve ter especial atenção a encampação pois, diante da discussão em torno da titularidade municipal do serviço, devem ser desenvolvidos mecanismos jurídicos para impedir que vicissitudes do poder local interfiram negativamente no devir da concessão, fazendo pulular desatinados atos de encampação. Outra questão que merece cuidados se refere à rescisão, caso advenham fatos que impeçam a plena atuação da concessionária (intercorrências de fato do príncipe sobre a financiabilidade do projeto, problemas ambientais incontornáveis). Como o artigo 39, Parágrafo Único da Lei $\mathrm{n}^{\circ} 8.987 / 95$, impede a interrupção do serviço no caso de rescisão, a equação entre continuidade e rescisão deve ser abordada na regulação.

\section{Prazos de concessão e condições para prorrogação dos contratos}

O prazo contratual deve ser estabelecido em conformidade com a modelagem de venda, pois interfere diretamente na precificação da empresa. Inobstante, devem ser consideradas as necessidades de amortização dos investimentos e a taxa de retorno. Não se pode descartar a hipótese de previsão de um prazo menor com possibilidade de sua prorrogação se atendidas as metas de qualidade e universalização que venham a ser estabelecidas na regulação.

\section{Os direitos e deveres dos usuários para obtenção e utilização dos serviços}

Ponto essencial, a regulação deve estipular uma ampla gama de direitos e obrigações para os usuários. Nisso devem estar compreendidas dimensões como as condições para fruição do serviço; a questão da possibilidade de opção pelo fornecimento de água versus a obrigatoriedade de utilização do serviço de esgotamento sanitário (por questão de saúde pública) nas localidades atingidas pela rede, e a consequiente questão da independência tarifária entre os dois serviços; os indicadores de potabilidade e de qualidade mínima da água fornecida; toda a gama de direitos do consumidor aplicados ao saneamento, incluindo o direito à adequada informação sobre o serviço.

Importante ter em vista duas ordens de consumidores: aqueles que já dispõem do saneamento e que devem ter assegurado seu direito à fruição de um serviço adequado, de qualidade e por preço justo; e, de outro lado, os consumidores potenciais, aqueles que não têm acesso ao saneamento e cujo principal direito se refere à universalização do serviço.

Além de algumas condições de recebimento e fruição, o principal dever do usuário se refere ao pagamento da tarifa. Aqui emergem duas ordens de problemas. O primeiro relacionado à definição da tarifa adequada, tendo em vista i) o dever de modicidade; ii) o seu impacto social; iii) a necessidade de investimentos na ampliação 
e melhora da rede; iv) o fato de que uma concentração tarifária nos maiores consumidores leva à esquiva do pagamento e à evasão de setores produtivos do Estado, tendo em vista que isenções tarifárias tornaram-se instrumentos para atração de investimentos. Na fixação da tarifa, deveria ser utilizado mecanismo segundo o qual todo avanço tecnológico, que resulte em diminuição dos custos do serviço, seja repassado ao consumidor, a exemplo do que é praticado nas telecomunicações brasileiras e na regulação norte-americana. Contudo, este repasse pode minorar os investimentos em infra-estrutura a serem efetuados pelos concessionários.

O segundo problema, central em termos regulatórios, se refere à interrupção dos serviços por falta de pagamento. Tal questão deve ser tratada em observância às decisões jurisprudenciais (inclusive do STF) e deve considerar, isoladamente, a) o serviço de esgoto em separado do serviço de abastecimento d'água; b) a essencialidade do serviço para a saúde pública; c) a situação econômica e os indicadores de desemprego da região. Neste sentido, podem ser desenvolvidos mecanismos de crédito tarifário, de períodos de moratória, bem como o procedimento prévio ao desligamento do serviço. Na Inglaterra, a questão tem sido resolvida com o estabelecimento de condições especiais de pagamento para "grupos vulneráveis de usuários": grandes famílias, com renda baixa, e usuários em condições médicas que requerem uso de grande volume de água. Outra questão a ser tratada é a vedação de subsídios cruzados. Neste sentido, pode-se cogitar que a concessão venha a ser onerosa e que o ônus pago reverta para um fundo de tarifa social, a ser aplicado na cobertura de déficits tarifários e no financiamento da inadimplência, evitando que tais encargos recaiam sobre a concessionária, o que pode inviabilizar seu negócio.

\section{Proposta de estabelecimento de critérios, indicadores, fórmulas e parâmetros sobre a qualidade dos serviços}

Devem ser estabelecidos parâmetros de aferição da qualidade do serviço, além da edição de um Plano de Metas de Qualidade. A vantagem da terceirização da execução dos serviços de saneamento básico para a iniciativa privada, consiste, entre outras, na possibilidade de dar maior ênfase aos indicadores e parâmetros de qualidade (resultado), em detrimento do controle do processo (meio), como era feito com as empresas estatais. Os indicadores devem levar em conta os padrões ambientais, sanitários e tecnológicos existentes no mercado. Porém, deve-se ter em vista que a mera transposição do estado da arte da tecnologia ambiental pode ser incompatível com o estágio de baixa penetração da rede e mesmo tornar inviável a modelagem do negócio.

\section{Critérios para o cálculo da forma de pagamento de indenizações às concessionárias}

É essencial fixar um critério de indenização que assegure ao investidor alguma segurança de expectativas. Porém, tal fixação deve ter em conta um regime que 
considere efetivamente a amortização do investimento e a depreciação dos bens, evitando que ao final do prazo de concessão restem ainda parcelas por indenizar. Essencial é a previsão de mecanismos fortes de indenização contra a extinção antes do prazo, desincentivando a adoção de medidas políticas impensadas. $O$ regime de indenização deve, portanto, ser estabelecido diferentemente em função de cada hipótese de extinção. A indenização no caso de encampação deve ser prevista na lei que a autorizar. Diante da questão municipal, é importante que a regulação assegure padrões mínimos para tal indenização.

\section{A solução das divergências contratuais entre o poder concedente e a concessionária}

Como autoriza a Lei $n^{\circ} 8.987 / 95$, o contrato de concessão deve prever mecanismos não jurisdicionais para solução de divergências. Forte parece ser a idéia de um Tribunal Arbitral do qual não participem membros do poder público municipal ou estadual, sem prejuízo do direito do poder concedente indicar alguns membros. Caso a modelagem regulatória caminhe para a outorga de várias concessões, pode ser estabelecido previamente um mesmo órgão arbitral com atribuição de resolver pendências de todos os contratos de concessão.

\section{O financiamento dos investimentos predominantemente de caráter social}

A questão do financiamento de metas de universalização desprovidas de perspectiva de retorno econômico constitui um tema regulatório central. Para tanto, podem concorrer fontes orçamentárias de programas da União, do Estado ou de Municípios, ou ainda de organismos multilaterais; financiamento pelo próprio fluxo de caixa da concessionária; ou recursos de fundo específico, a ser constituído por lei, e que seria integrado por contribuiçōes compulsórias das próprias prestadoras. As condicionantes de cada um destes mecanismos já foram acima antecipadas. Porém, parece uma diretriz válida que se separe a fonte de financiamento da política tarifária.

\section{Conclusão}

Certamente todas estas notas demandam reflexão e afincamento. $O$ que surpreende é que os processos de privatização do setor de saneamento, levados a cabo até agora no país, estejam desconsiderando totalmente a maioria destes marcos regulatórios. Privatizar empresas que atuam na prestação de serviços essenciais, como saneamento, não pode significar a desregulação do setor. Não pode ser visto como um mero negócio. E, infelizmente, assim tem sido. 